\title{
The Lipid Composition of the Psychrophilic Bacterium Micrococcus cryophilus
}

\author{
By N. J. RUSSELL \\ Sub-department of Chemical Microbiology, Department of Biochemistry, \\ University of Cambridge
}

(Received 27 June 1973; revised 13 August 1973)

SUMMAR Y

The lipid composition of the psychrophilic bacterium Micrococcus cryophilus (ATCC I5I74) has been examined. The chloroform-methanol extractable (i.e. 'free') lipid represents nearly 10\% of the bacterial mass and is composed of $85 \%$ polar lipid and I $5 \%$ neutral lipid. The polar lipid consists of $46 \%$ phosphatidyl ethanolamine, $43 \%$ phosphatidyl glycerol and $9 \%$ cardiolipin, plus a fourth unidentified minor component which cannot be detected in all extracts. The neutral lipid is characterized by the presence of a mixture of simple waxes, which constitute $86 \%$ of this fraction, together with smaller amounts of free fatty acids, alcohols and a ubiquinone, probably $\mathrm{Q}_{8}$. Simple waxes have not been found previously in such large amounts in true bacteria. The implications of the results of the lipid analysis are discussed with regard to the taxonomic position of $M$. cryophilus.

\section{INTRODUCTION}

Micrococcus cryophilus was isolated in 195I by McLean, Sulzbacher \& Mudd, who described it as a Gram-variable Micrococcus. Mazanec, Kocur \& Martinec (1966) demonstrated by electron microscopy the presence of a typical Gram-negative envelope in this organism, and it has been excluded from the Gram-positive genus Micrococcus on the basis of the GC content of its DNA, which is rather lower than most other micrococci (Boháček, Kocur \& Martinec, 1967). Nor does $M$. cryophilus fit any of the eight subgroups of micrococci proposed by Baird-Parker (I965).

There are certain broad differences in the lipid composition of Gram-negative and Grampositive bacteria, and fatty acid composition has been used as an aid to classification. The chloroform-methanol-extractable lipids of Micrococcus cryophilus contain even numbered, saturated and mono-unsaturated fatty acids, whereas the lipid fraction that is extractable with organic solvents only after saponification is characterized by hydroxy fatty acids (Russell, I97I). This is typical of Gram-negative bacteria and provides further evidence that $M$. cryophilus is Gram-negative.

The present report concerns the composition of the chloroform-methanol-extractable lipids of Micrococcus cryophilus, both with regard to its taxonomic position and as part of a study into the relationship between the lipid composition and the psychrophilic habitat of this bacterium.

\section{METHODS}

Organism. The bacterium used in this study was a strain of Micrococcus cryophilus (ATCC I 5 I74), obtained from Dr N. L. Malcolm.

Cultures. Bacteria were grown in a Casamino acids-salts medium modified after Malcolm (I968): $100 \mathrm{~mm}$-tris, $80 \mathrm{~mm}-\mathrm{NaCl}, 20 \mathrm{~mm}-\mathrm{KCl}, 20 \mathrm{~mm}-\mathrm{NH}_{4} \mathrm{Cl}, 0.64 \mathrm{~mm}-\mathrm{KH}_{2} \mathrm{PO}_{4}, 0.16 \mathrm{~mm}-$ $\mathrm{Na}_{2} \mathrm{SO}_{4}, 0 \cdot \mathrm{I} \mathrm{mM}^{-\mathrm{CaCl}_{2}}$, I mM- $\mathrm{MgCl}_{2} .6 \mathrm{H}_{2} \mathrm{O}$, adjusted to $\mathrm{pH} 7 \cdot 4$ with $\mathrm{H}_{2} \mathrm{SO}_{4}$ and supple- 
mented with $0.5 \%$ Difco Casamino acids (Difco Laboratories, West Molesley, Surrey) prior to use. This medium is referred to as 'NM medium'; 'NM buffer' had the same composition as NM medium, with Casamino acids omitted.

Cultures were maintained at $4{ }^{\circ} \mathrm{C}$ on plates of NM medium containing $2 \%$ agar. They were grown at 20 or $5^{\circ} \mathrm{C}$ in $500 \mathrm{ml} \mathrm{NM}$ medium dispensed in 21 conical flasks shaken at I $80 \mathrm{rev} . / \mathrm{min}$ in a refrigerated orbital incubator (Gallenkamp I $\mathrm{H} \mathrm{400).} \mathrm{Growth} \mathrm{was} \mathrm{esti-}$ mated from the extinction at $600 \mathrm{~nm}\left(E_{600}\right)$ using a Unicam SP 500 spectrophotometer; an $E_{600}$ of unity corresponded to a density of $300 \mu \mathrm{g}$ dry wt bacteria/ml.

Bacteria were harvested by centrifugation at the growth temperature for 3 min at $15000 \mathrm{~g}$ in a MSE High Speed I 8 centrifuge and washed once with NM buffer.

In order to obtain a quantitative estimate of the neutral lipid components, organisms were grown in NM buffer supplemented with a mixture of radioactive amino acids derived from an algal protein hydrolysate diluted with $5 \mathrm{~g} / \mathrm{l}$ of a mixture of 'cold' amino acids in the same proportions as in the algal protein hydrolysate, in place of Casamino acids. Fifty $\mu \mathrm{Ci}$ of radioactive amino acids were added to $200 \mathrm{ml}$ of growing culture, which represented an 800 -fold dilution of radioactive amino acids. Bacterial samples ( $0.1 \mathrm{mg}$ dry wt) were filtered, dried and counted as a measure of the incorporation into whole cells. At the same time $30 \mathrm{ml}$ samples of culture were withdrawn and centrifuged, and the lipids extracted with chloroform-methanol $(2: \mathrm{I}, \mathrm{v} / \mathrm{v})$, washed with saline and the whole sample counted.

Extraction of lipids. The washed pellet ( $0.5 \mathrm{~g}$ approx.) was resuspended in $25 \mathrm{ml}$ methanol and an equal volume of chloroform added. After $4 \mathrm{~h}$ the suspension was filtered through a sintered glass funnel (porosity 4 or 5 ), and the residue re-extracted overnight with $50 \mathrm{ml}$ chloroform-methanol $(2: \mathrm{I}, \mathrm{v} / \mathrm{v})$ and refiltered. The pooled filtrates were evaporated to dryness at low pressure using a rotary evaporator. Non-lipid contaminants were removed by passage through Sephadex G-25 (Wells \& Dittmer, 1963) unless otherwise stated. This extract, termed 'free lipid', was stored at $-20{ }^{\circ} \mathrm{C}$.

Fractionation of polar and neutral lipids. Samples of free lipid dissolved in a small volume of chloroform were applied to a $\mathrm{I} O \times \mathrm{I} \mathrm{cm}$ column of celite-silicic acid $(2: \mathrm{I}, \mathrm{w} / \mathrm{w})$, which had been extensively washed with chloroform-methanol $(2: \mathrm{I}, \mathrm{v} / \mathrm{v})$ and equilibrated in chloroform. A neutral lipid fraction was eluted with four column volumes of chloroform and the polar lipid with four column volumes of chloroform-methanol ( $\mathrm{I}: 2, \mathrm{v} / \mathrm{v})$. Thinlayer chromatography of the resulting two fractions demonstrated the absence of crosscontamination.

Mild alkaline hydrolysis of the wax ester fraction, obtained by preparative thin-layer chromatography of the neutral lipid fraction, was performed by refluxing in $3 \mathrm{~N}$-methanolic potassium hydroxide for $30 \mathrm{~min}$. Two volumes of water were added, the $\mathrm{pH}$ value adjusted to below 4 with conc. $\mathrm{HCl}$ and the hydrolysis products extracted with diethyl ether. The ether solution was washed twice with water, dried over anhydrous $\mathrm{Na}_{2} \mathrm{SO}_{4}$ and evaporated to dryness in vacuo.

Analysis of polar and neutral lipids. Lipids were separated by thin-layer chromatography using silica gel $\mathrm{G}$; the thickness of the silica gel was $0.25 \mathrm{~mm}$ for analytical work and I mm for preparative thin-layer chromatography. Plates were activated just prior to use by heating at $100{ }^{\circ} \mathrm{C}$ for $\mathrm{I} \mathrm{h}$. For argentation thin-layer chromatography the silica gel slurry was made up in $5 \%$ silver nitrate solution instead of water (Morris, 1964). Activated chromatograms for reversed phase thin-layer chromatography were impregnated with liquid paraffin by slowly immersing in $8 \%$ liquid paraffin in petroleum ether (b.p. 40 to $60{ }^{\circ} \mathrm{C}$ ); the plates were removed, the petrol was allowed to evaporate in an air stream, and the plates were used immediately. 
The following solvents were used: solvent A, chloroform-methanol-7N-ammonia (65:30:4, by vol.); solvent $B$, chloroform-methanol-acetic acid-water ( $85: 15: 10: 3.5$ by vol.); solvent, $\mathrm{C}$, chloroform-methanol-water ( $65: 25: 4$ by vol.); solvent $\mathrm{D}, 4 \%$ diethyl ether in petroleum ether (b.p. 40 to $60^{\circ} \mathrm{C}$ ); solvent E, $15 \%$ diethyl ether in petroleum ether (b.p. 40 to $60{ }^{\circ} \mathrm{C}$ ); solvent $\mathrm{F}$, petroleum ether (b.p. 40 to $60^{\circ} \mathrm{C}$ )-diethyl ether-formic acid (85: I5: I, by vol.). Lipid components on preparative plates were first visualized with iodine vapour, outlined with a needle and the iodine sublimed away before scraping the component bands into quickfit test-tubes. Each component was eluted with three changes of diethyl ether: the solvent was removed in an air stream.

The solvent system used for reversed phase thin-layer chromatography of the ubiquinones was $8 \%$ water in acetone containing enough liquid paraffin to saturate the system, which was shaken vigorously prior to chromatography.

If components were to be analysed further they were visualized either directly with iodine vapour or by spraying with $0.5 \%$ rhodamine $6 \mathrm{G}$ in $95 \%$ ethanol and viewing under an ultraviolet lamp at $350 \mathrm{~nm}$. For a permanent record, plates were sprayed with $0.6 \%$ $\mathrm{Na}_{2} \mathrm{Cr}_{2} \mathrm{O}_{7}$ in $55_{0}^{\circ} \mathrm{H}_{2} \mathrm{SO}_{4}(\mathrm{w} / \mathrm{v})$ and charred in an oven at $160^{\circ} \mathrm{C}$. In order to detect ultraviolet absorbing substances, plates were sprayed with $0.1 \% 2,4$-dichlorfluorescein in $95 \%$ ethanol and viewed under an ultraviolet lamp at $254 \mathrm{~nm}$ or $350 \mathrm{~nm}$.

Phosphorus-containing lipids were detected using the phosphate spray of Dittmer \& Lester (1964): to visualize lipids having free amino groups, plates were sprayed with $0.5 \%$ ninhydrin in ethanol and heated at $105{ }^{\circ} \mathrm{C}$ for $20 \mathrm{~min}$; the Schiff-periodate test was used to detect vicinal glycol-containing lipids (Shaw, I 968 ).

Components co-chromatographed with or had the same $R_{F}$ values when tested alongside authentic standards in one-dimensional separations. The following standards were available: phosphatidyl ethanolamine and diphosphatidyl glycerol (General Biochemicals, Chagrin Falls, Ohio. U.S.A.), phosphatidyl glycerol and purified octadecanol (gift of Dr M. I. Gurr), and ubiquinones 7, 9 and Io (gift of Dr P. J. Dunphy). The wax esters oleyl oleate and oleyl stearate were synthesized.

For estimation of phospholipid, spots containing phosphorus were aspirated directly into a Kjeldahl flask containing $0.9 \mathrm{ml}$ perchloric acid (sp. gr. I.70) and digested for $20 \mathrm{~min}$. After cooling, the phosphorus content was determined according to the method of Marinetti (1962).

For estimation of radioactivity, samples were quantitatively transferred directly into scintillation vials as described by Björkerud (1969). Ten $\mathrm{ml}$ BBOT-toluene scintillant (4 $\mathrm{g}$ BBOT/1 toluene) were added and the radioactivity determined in a Packard Model 3375 TriCarb liquid scintillation spectrometer. For lipid samples adsorbed onto gel the efficiency of counting ${ }^{14} \mathrm{C}$ was $67 \%$.

Gas liquid chromatography. Fatty acids and alcohols were analysed by gas liquid chromatography using a Pye series I04 chromatograph equipped with dual flame ionisation detectors, and polar and non-polar columns. Before analysis fatty acids were converted to their methyl esters using the methanol-benzene-sulphuric acid transmethylating mixture of Nichols \& Moorhouse (1969). Fatty acid methyl esters were separated on a $9 \mathrm{ft} \times \frac{1}{4}$ in glass column containing 10\% FFAP (free fatty acid phase, Phase Separations Ltd, K. J. Clarke $\&$ Co., Sudbury, Suffolk) supported on 100 to $\mathrm{I} 20$ mesh celite at $185^{\circ} \mathrm{C}$, using a nitrogen flow rate of $60 \mathrm{ml} / \mathrm{min}$ and a detector temperature of $300{ }^{\circ} \mathrm{C}$. Alternatively a $5 \mathrm{ft} \times \frac{1}{4}$ in glass column containing I0\% PEGA (polyethylene glycol adipate) on 100 to I 20 mesh diatomite $\mathrm{C}$ was used isothermally at $\mathrm{I} 85^{\circ} \mathrm{C}$ with an argon flow rate of $45 \mathrm{ml} / \mathrm{min}$. Identifications were confirmed using a $9 \mathrm{ft} \times \frac{1}{4}$ in glass column packed with $10 \%$ SE-30 (silicone gum) supported 
Table I. $R_{F}$ values for phospholipids of Micrococcus cryophilus in three solvent systems

\begin{tabular}{lccc}
\multicolumn{1}{c}{ three solvent systems } & \multicolumn{3}{c}{$R_{F}$ values } \\
\cline { 2 - 3 } \multicolumn{1}{c}{ Solvent system } & $\mathrm{A}$ & $\mathrm{B}$ & $\mathrm{C}$ \\
Cardiolipin & 0.17 & 0.90 & 0.75 \\
Phosphatidyl ethanolamine & 0.36 & 0.68 & 0.43 \\
Unknown & $\mathrm{ND}$ & 0.48 & 0.25 \\
Phosphatidyl glycerol & 0.15 & 0.44 & 0.18
\end{tabular}

ND, not detected.

Bacteria were grown in NM medium; their lipid was extracted, and non-lipid contaminants removed with Sephadex G-25 before fractionating into polar and neutral lipids using silicic acid column chromatography. Samples of polar lipid were applied to silica gel $\mathrm{G}$ plates and components separated using the following solvent systems: A, chloroform-methanol-7 N-ammonia $(65: 30: 4$, by vol.); B, chloroform-methanol-acetic acidwater $(85: 15: 10: 3.5$ by vol.); $C$, chloroform-methanol-water $(65: 25: 4$, by vol.). Spots were visualized by charring.

on 85 to 100 mesh Chromosorb W at $220^{\circ} \mathrm{C}$, with a nitrogen flow rate of $60 \mathrm{ml} / \mathrm{min}$ and a detector temperature of $300{ }^{\circ} \mathrm{C}$. Alcohols were analysed without modification using the SE-30 column.

Relative amounts of each component were determined by estimating the area of each peak by triangulation (peak height $\times$ peak width at half height). Peaks were identified by comparison of their retention times with those of authentic standards, and in some instances co-chromatography with standards.

Fatty acid standards were obtained from the Hormel Institute, Austin, Minnesota, U.S.A., and were found to be $>99 \%$ pure by gas liquid chromatographic analysis.

Materials. A mixture of radioactive amino acids (uniformly ${ }^{14} \mathrm{C}$-labelled), derived from an algal protein hydrolysate, was obtained from The Radiochemical Centre, Amersham, Buckinghamshire. All chemicals used were of AnalaR grade, or the equivalent. Organic solvents were redistilled once before use.

\section{Free lipid content}

\section{RESULTS}

Gravimetric determination of the free lipid content of Micrococcus cryophilus showed that as the growth temperature was lowered from 20 to $5{ }^{\circ} \mathrm{C}$ the free lipid content increased from $8 \cdot 4 \pm 0 \cdot 7 \%(n=6)$ to $9 \cdot 7 \pm 0.7 \%(n=4)$ of the dry weight. There was no change in the lipid content during the growth in batch culture. 'Free' lipid represents that lipid obtained by two chloroform-methanol extractions; neither subsequent chloroformmethanol extractions, nor refluxing with methanol or isopropanol, removed further lipid. The free lipid consisted of $85.7 \%$ polar and $\mathrm{I} 43 \%$ neutral lipid on the basis of a gravimetric analysis. These proportions did not vary significantly with growth temperature.

\section{Phospholipid composition}

Three of the four phospholipids separated by thin-layer chromatography (Table I) were identified by a combination of specific sprays and the use of authentic standards as detailed in Methods. Phosphatidyl ethanolamine and phosphatidyl glycerol in approximately equal amounts were the major phospholipids, together with 9 to $10 \%$ cardiolipin. The identity of the fourth component has not been determined; it contained phosphorus and at least one free amino group, but no vicinal hydroxyl groups. On the basis of its phosphorus content it was a minor component $(<2 \%)$ and it was not detected on all chromatograms. The relative 
Table 2. Effect of growth temperature and phase of growth on the relative phospholipid composition of Micrococcus cryophilus

Growth temperature $\left({ }^{\circ} \mathrm{C}\right)$ :

Harvest $E_{600}$ :

Relative phospholipid composition

$\begin{array}{rrr}0.12 & 0.55 & 1 \cdot 20 \\ 9.6 & 9 \cdot 1 & 9 \cdot 9 \\ 45.2 & 46.9 & 46 \cdot 7 \\ 45.2 & 43.9 & 43 \cdot 3\end{array}$

\begin{tabular}{rrr}
\multicolumn{3}{c}{5} \\
2.40 & 0.35 & 2.61 \\
9.0 & 8.9 & 9.7 \\
47.3 & 46.8 & 46.7 \\
43.6 & 44.3 & 43.6
\end{tabular}

Organisms were grown in NM medium at 5 or $20^{\circ} \mathrm{C}$ and harvested at different times during the exponential phase; $E_{600}=1.2$ to 1.5 was equivalent to mid-exponential phase, and $E_{600}=2.5$ to 2.8 late exponential phase. Lipid was extracted with chloroform-methanol mixtures, and non-lipid contaminants removed by passage through Sephadex G-25. The three major phospholipids were separated by thin-layer chromatography on silica gel $G$ using chloroform-methanol-acetic acid-water (85:15:10:3.5, by vol.) as solvent system. Lipid samples were analysed in duplicate and the phosphorus content of each spot determined. The phospholipid composition is expressed in terms of the relative amounts of phosphorus in the three major phospholipids, which usually represented $>95 \%$ of the phosphorus content of the sample applied.

Table 3. $R_{F}$ values of neutral lipid components in three solvent systems

\begin{tabular}{lccc} 
& \multicolumn{3}{c}{$R_{F}$ values for solvent system } \\
& D & E & F \\
Wax ester & 0.81 & 0.96 & 0.96 \\
Ubiquinone & 0.12 & 0.37 & 0.71 \\
Alcohol & 0.08 & 0.08 & 0.24 \\
Unesterified fatty acid & 0.03 & 0.03 & 0.43
\end{tabular}

Polar and neutral lipids were separated as in Table I. Samples of neutral lipid were applied to silica gel G plates and components separated using the following solvent systems: $\mathrm{D}, 4 \%$ diethyl ether in petroleum ether (b.p. 50 to $60^{\circ} \mathrm{C}$ ); E, $15 \%$ diethyl ether in petroleum ether (b.p. 40 to $60{ }^{\circ} \mathrm{C}$ ); F, petroleum ether (b.p. 40 to $60^{\circ} \mathrm{C}$ )-diethyl ether-formic acid (85:15:I, by vol.). Spots were visualized by charring.

proportions of the three major phospholipids did not vary significantly during the growth in batch culture, nor with the temperature of growth (Table 2). No glycolipids were detected using the Schiff-periodate test.

\section{Neutral lipid composition}

Four neutral lipid components were separated in three solvent systems (Table 3). By reference to authentic standards they were tentatively identified as wax ester, ubiquinone, free fatty acid and alcohol. The spot corresponding to ubiquinone fluoresced strongly after spraying with 2,4 -dichlorfluorescein, more so at $254 \mathrm{~nm}$ than at $350 \mathrm{~nm}$; the spots corresponding to the alcohol and free fatty acid also fluoresced, but to a smaller extent.

To confirm these tentative assignations samples of the four components were isolated for further analysis by preparative thin-layer chromatography using solvent F.

A sample of the suspected wax ester was subjected to mild alkaline hydrolysis. The hydrolysis products were analysed by thin-layer chromatography using solvents $\mathrm{E}$ and $\mathrm{F}$. On the basis of their $R_{F}$ values and co-chromatography with standards the hydrolysis products were identified as free fatty acid and alcohol. Samples of the wax-ester-derived free fatty acids and alcohols were obtained by preparative thin-layer chromatography and further analysed by gas liquid chromatography. The fatty acid and alcohol composition of the wax ester fraction was similar to that of the total extractable fatty acids (Russell, I97r), except for a higher proportion of saturated alcohols than saturated fatty acids (Table 4). It was evident 
Table 4. Fatty acid and alcohol composition of the wax ester fraction of the neutral lipid of Micrococcus cryophilus

$\begin{array}{cccc}\begin{array}{c}\text { Identity of } \\ \begin{array}{c}\text { alcohol of } \\ \text { fatty acid }\end{array}\end{array} & \begin{array}{c}\text { Alcohols } \\ \text { SE-30 }\end{array} & \overbrace{\text { SE-30 }}^{\text {Fatty acids }} & \text { FFAP } \\ \text { 16:0 } & 10.8 & 9.3 & 6.3 \\ \text { 16: } & 6.9 & 23.4 & 24.6 \\ \text { 18:0 } & 17.6 & 4.7 & \text { Trace* } \\ \text { I8: } & 64.8 & 62.5 & 69.1\end{array}$

Bacteria were grown in NM medium at $20^{\circ} \mathrm{C}$; their lipid was extracted, purified and separated into polar and neutral fractions. The neutral lipid components were isolated by preparative thin-layer chromatography using petrol-ether-formic acid ( $85: 15: 1$, by vol.) as solvent system. The wax ester fraction was converted to its component alcohols and fatty acids by mild alkaline hydroysis. Fatty acids were transmethylated prior to analysis by gas liquid chromatography, and the alcohols analysed directly. Sample compositions are expressed as relative percentages of the total area beneath the chromatographic trace.

* Trace components represented $<1 \%$ of total area beneath chromatographic trace.

that the fatty acids and alcohols were derived from a mixture of waxes. Some insight into the combinations present was obtained by argentation thin-layer chromatography of the intact wax ester fraction (Haati, Nikkari \& Juva, 1963), when two spots only were obtained, corresponding to wax esters containing one or two double bonds per molecule. This confirmed that the wax ester fraction consisted of a 'family' of waxes. This result was supported by mass spectrometry, which revealed three major molecular ions corresponding to waxes containing both unsaturated alcohol and fatty acid, and waxes containing a saturated alcohol and unsaturated fatty acid, as well as the appropriate fragment ions.

The ultraviolet spectrum of the suspected ubiquinone in the oxidized form in Spectrosil solvent grade cyclohexane gave a single absorption maximum at $275 \mathrm{~nm}$, which was virtually abolished by reduction with borohydride; this is characteristic of such compounds (Lester, Hatefi, Widmer \& Crane, I959). To determine whether more than one ubiquinone was present, the ubiquinone fraction from Micrococcus cryophilus was analysed by reversedphase thin-layer chromatography using $Q_{7}, Q_{9}$ and $Q_{10}$ as markers. A single spot only was obtained, which had an $R_{F}$ value of 0.28 . It ran between $\mathrm{Q}_{7}\left(R_{F} 0.34\right)$ and $\mathrm{Q}_{9}\left(R_{F} 0.20\right)$ and thus appeared to be $Q_{8}$, although $Q_{7(\text { II) }}$ (i.e. $Q_{7}$ with one of its double bonds saturated) also would run in this position (Dunphy, Phillips \& Brodie, 197I). $\mathrm{Q}_{8}$ would be a more likely assignation than the alternative $\mathrm{Q}_{7(\mathrm{H})}$, since $\mathrm{Q}_{8}$ is the most commonly identified ubiquinone in Gram-negative bacteria (Lester \& Crane, 1959; Bishop, Pandya \& King, 1962).

The suspected free fatty acid fraction was analysed by gas liquid chromatography. The relative proportions of the fatty acids were similar to those of the total lipid extract; the major components were $I 8: I(70.8 \%)$ and $I 6: I(24.8 \%)$ with $4.8 \%$ of $I 6: 0$ and trace amounts of $\mathrm{I} 8: 0$.

The suspected free alcohol was not analysed further as it proved difficult to obtain enough material from preparative thin-layer chromatograms.

From charred chromatograms it was obvious that the major neutral lipid component was the wax ester fraction, but in order to obtain a quantitative estimate the organism was grown in the presence of a mixture of radioactive amino acids, as described in Methods. The mean generation time was $3 \frac{1}{4} \mathrm{~h}$ (the same as that in NM medium) and incorporation into whole organisms and lipids increased linearly with growth. Incorporation of ${ }^{14} \mathrm{C}$ continued after I $\mathrm{h}$ and it was presumed that after three to four generations the bacteria were steady state 
labelled. Since the organism derives all its carbon from amino acids and since these were initially at identical specific activities, it was assumed that all components were labelled to the same extent, irrespective of their precursor pools. After 12 hour's growth in the presence of radioactive amino acids a parallel culture was harvested, washed once with NM buffer, and the lipid extracted and fractionated into polar and neutral lipid. The four neutral lipid components were separated by thin-layer chromatography and their radioactivity measured. Recovery of radioactivity from such plates always represented $>9 \mathrm{I} \%$ of that applied to the chromatogram. The wax ester was the major component $(85$ to $86 \%$ ) of the neutral lipid of this organism; smaller amounts of ubiquinone ( 5 to $6 \%$ ) and free fatty acid ( 6 to $7 \%$ ) were present also, and the alcohol was a minor component ( $\mathrm{I} \cdot 8$ to $2 \cdot \mathrm{I} \%$ ).

A sample of ${ }^{14} \mathrm{C}$-labelled, unfractionated lipid was chromatographed using solvent $\mathrm{B}$. The relative amounts of polar and neutral lipid were established by measuring the radioactivity in the three phospholipid spots and in the solvent front (neutral lipid). This gave a value of I $5.4 \%$ neutral lipid, which confirmed the results of the gravimetric analysis ( $14.3 \%$ ) above. The proportions of individual phospholipids were also the same as those obtained by phosphorus estimations on an identical sample chromatogrammed on the same plate. Recovery of radioactivity from the plate was $98 \cdot 4 \%$.

\section{DISCUSSION}

Micrococcus cryophilus has been placed in a Gram-positive genus, but the amount and composition of its lipid (the chloroform-methanol extractable lipid represents nearly I0 \% of its mass) are more typical of Gram-negative bacteria than of Gram-positive, possibly due to the presence of a second membrane. The free lipid contains even numbered saturated and mono-unsaturated fatty acids (Russell, 1971). Some of the lipid is not chloroformmethanol extractable and is characterized by the presence of hydroxy fatty acids (Russell, I97I). The neutral lipid contains the pigment ubiquinone, but not vitamin $\mathrm{K}$.

The amount and nature of the phospholipids remain constant during growth in batch culture. Although the relative proportions of the phospholipids are unaffected by a decrease in growth temperature, their total amount increases slightly. Hunter \& Rose (1972) observed a similar effect in the yeast Saccharomyces cerevisiae and suggested that the increased phospholipid content could represent an adaptation to growth at low temperatures in view of the cation binding properties of phospholipids such as phosphatidyl choline (Diamond \& Rose, 1970). In many Gram-negative bacteria temperature has no effect on the phospholipid content (see for example Cullen, Phillips \& Shipley, I971). It is possible that the observed increase in phospholipid content in Micrococcus cryophilus when the growth temperature is lowered may not be a direct temperature effect. The growth rate of $M$. cryophilus slows as the temperature is lowered and Ballesta \& Schaechter (1972) showed for Escherichia coli that the rate of phospholipid synthesis was inversely proportional to the growth rate; in Bacillus megaterium also the lipid content increased as the growth rate decreased (Sud \& Schaechter, 1964).

Preliminary experiments using cells doubly labelled with ${ }^{32} \mathrm{P}$ and $\left[{ }^{14} \mathrm{C}\right] \mathrm{glycerol}$ indicate that the phospholipids in Micrococcus cryophilus are very stable, less than $10 \%$ of both the ${ }^{14} \mathrm{C}$ and ${ }^{32} \mathrm{P}$ turning over in one generation. The fatty acids are not labelled so this conclusion may not be valid for this moiety of the phospholipids. Slow turnover rates have been observed for the major phospholipids in other bacteria, such as Escherichia coli (Cronan \& Vagelos, 1972) and Rhodopseudomonas spheroides (Gorchein, Neuberger \& Tait, I968). Makula \& Finnerty (I97I) showed in $M$. cerificans that phosphatidyl ethanolamine did not turn over, 
while phosphatidyl glycerol and cardiolipin turned over very slowly indeed: it may be significant that $M$. cerificans, like $M$. cryophilus, is a Gram-negative micrococcus.

In common with most bacteria the neutral lipid of Microccoccus cryophilus represents a minor fraction ( $15 \%$ approx.) of the free lipid. However, it is noteworthy that $86 \%$ of the neutral lipid consists of a mixture of 'true' waxes (Deuel, I95l), which therefore represent $13 \%$ of the free lipid of this organism. Simple waxes of this nature have not been reported previously in such large amounts in the true bacteria, although their presence has been inferred in Bacillus cereus (Kates, Kushner \& James, 1962) and Serratia marcescens (Kates, Adams \& Martin, I964). They are found in Nocardia species (Lanéelle, Asselineau \& Castelnuovo, 1965) and in the Corynebacteria and Mycobacteria, which also contain large amounts of unique high molecular weight complex waxes (Asselineau, I966). Preliminary experiments using spheroplast membranes derived from $M$. cryophilus suggest that the waxes are part of the envelope; it would be interesting to know their exact locale in this complex structure, since it is possible that these lipids may have a special role to play in membrane structure or function. The wax esters are rather more saturated than the phospholipids; approximately $10 \%$ of the wax fatty acids and nearly $30 \%$ of the wax alcohols are saturated, compared with a value of I to $2 \%$ for the phospholipid fatty acids. The waxes would be less fluid than the phospholipids and may be important in the structural framework of the envelope, or they may provide discrete, less mobile regions within the envelope. It has been suggested (Oldfield, Chapman \& Derbyshire, 1972) that organisms such as bacteria, whose membranes lack cholesterol, must necessarily have liquid and gel-like regions in their membranes in order to regulate permeability.

The discovery of such waxes in Micrococcus cryophilus is interesting from a taxonomic standpoint. The organism is not a micrococcus and bears more resemblance to members of the genus Acinetobacter (Dr M. J. Thornley, personal communication). The finding of waxes in three Acinetobacter species by Gallagher (I97I), as well as in M. cryophilus in the present study, may be taken as further evidence that these organisms are related. The failure to detect hydrocarbons in the neutral lipid of $M$. cryophilus is also consistent with the data of Morrison, Tornabene \& Kloose (1971), who found aliphatic hydrocarbons in true Grampositive micrococci but not Micrococcus cerificans.

I am grateful to Professor E. F. Gale and Dr D. Kerridge for their interest and for reading the manuscript. I thank Unilever Research Laboratories for providing facilities at Colworth House, Bedford where some of the work was performed during the tenure of a Cooperative Award in Pure Science awarded by the Science Research Council. Mass spectrometry of the wax esters was carried out by Dr W. Kelly of Unilever Research Laboratories, whom I wish to thank.

\section{REFERENCES}

Asselineat, J. (1966). The Bacterial Lipids. Paris: Herman.

BaIRd-PARKER, A. C. (1965). The classification of Staphylococci and Micrococci from World-wide sources. Joumal of General Microbiology 38, 363-387.

Ballesta, J. P. G. \& Schaechter, M. (I972). Dependence of the rate of synthesis of phosphatidyl ethanolamine and phosphatidyl glycerol on the rate of growth of Escherichia coli. Journal of Bacteriology $\mathbf{1} \mathbf{1 0}$, $452-453$.

Bishop, D. H. L., PAndya, K. P. \& KING, H. K. (I 962). Ubiquinone and Vitamin K in bacteria. Biochemical Jomnal 83, 606-6I4.

BJörkerUd, S. ( 1969). Simple scraper for thin-layer chromatograms. Journal of Lipid Research 10, 459-460. BohÁČeK, J., KoCUR, M. \& MARTINEC, T. (I967). DNA base composition and taxonomy of some Micrococci. Jounal of General Microbiology 46, 369-376. 
Cronan, J. E. \& VAgelos, P. R. (1972). Metabolism and function of the membrane phospholipids of Escherichia coli. Biochimica et biophysica acta 265, 25-60.

Cullen, J., Phillips, M. C. \& Shipley, G. G. (1971). The effects of temperature on the composition and physical properties of the lipids of Pseudomonas fluorescens. Biochemical Journal 125, 733-742.

Deuel, H. J. (195I). The Lipids, Vol. I, p. 3. New York: Interscience.

Diamond, R. J. \& Rose, A. H. (I970). Osmotic properties of spheroplasts from Saccharomyces cerevisiae grown at different temperatures. Journal of Bacteriology 102, 3I I-3I9.

Dittmer, J. C. \& Lester, R. L. (I964). A simple, specific spray for the detection of phospholipids on thin-layer chromatograms. Journal of Lipid Research 5, 126-1 27.

Dunphy, P. J., Phillips, P. G. \& Brodie, A. F. (197I). Separation and identification of menaquinones from microorganisms. Journal of Lipid Research 12, 442-449.

Gallagher, I. H. C. (I97I). Occurrence of waxes in Acinetobacter. Journal of General Microbiology 68, $245-247$.

Gorchein, A., Neuberger, A. \& Tait, G. H. (1968). Metabolic turnover of the lipids of Rhodopsendomonas spheroides. Proceedings of the Royal Society B r7o, 3I I-3 I 8.

HaAti, E., Nikkari, J. \& Juva, K. (1963). Fractionation of serum and skin sterol esters and skin waxes with chromatography on silica gel impregnated with silver nitrate. Acta chemica scandinavica r7, 538-540.

Hunter, K. \& Rose, A. H. (1972). Lipid composition of Saccharomyces cerevisiae as influenced by growth temperature. Biochimica et biophysica acta 260, 639-653.

Kates, M., Adams, G. A. \& Martin, S. M. (1964). Lipids of Serratia marcescens. Canadian Journal of Biochemistry 42, 46I-479.

Kates, M., Kushner, D. J. \& James, A.T. (I962). The lipid composition of Bacillus cereus as influenced by the presence of alcohols in the culture medium. Canadian Journal of Biochemistry and Physiology 40, 83-94.

LanéElle, M-A., Asselineau, J. \& Castelnuovo, G. (1965). Études sur les Mycobactéries et les Nocardiae. IV. Composition des lipids de Mycobacterium rhodocrous, $M$. pellegrino sp., et de quelques souches de Nocardiae. Annales de l'Institut Pasteur Io8, 69-82.

Lester, R. L. \& CRANE, F. L. (1959). The natural occurrence of coenzyme Q and related compounds. Journal of Biological Chemistry 234, $2164-2174$.

Lester, R. L., Hatefi, Y., Widmer, C. \& Crane, F. L. ( I959). Studies on the electron transport system. XX. Chemical and physical properties of the coenzyme $\mathrm{Q}$ family of compounds. Biochimica et biophysica acta 33, I69-1 85 .

Makula, R. A. \& FinNerty, W.R. (1971). Microbial assimilation of hydrocarbons: phospholipid metabolism. Journal of Bacteriology 107, 806-8I4.

MalCOLM, N. L. (1968). A temperature-induced lesion in amino acid-transfer ribonucleic acid attachment in a psychrophile. Biochimica et biophysica acta $\mathbf{1 5 7}, 493-503$.

MARINETti, G. V. (1962). Chromatographic separation, identification, and analysis of phosphatides. Journal of Lipid Research 3, I-20.

Mazanec, K., Kocur, M. \& Martinec, T. (I966). Electron microscopy of ultrathin sections of Micrococcus cryophilus. Canadian Journal of Microbiology 12, 465-469.

Mclean, R. A., Sulzbacher, W. L. \& Mudd, S. (I95I). Micrococcus cryophilus spec. nov.; A large coccus especially suitable for cytologic study. Journal of Bacteriology 62, 723-728.

Morris, L. J. (1964). New Biochemical Separations, pp. 295-319. Edited by A. T. James and L. J. Morris. London: Van Nostrand.

Morrison, S. J., Tornabene, T. G. \& Kloose, W. E. (1971). Neutral lipids in the study of relationships of members of the family Micrococcaceae. Journal of Bacteriology 108, 353-358.

Nichols, B. W. \& Moorhouse, R. (i969). The separation, structure and metabolism of monogalactosyl diglyceride species in Chlorella vulgaris. Lipids 4, 31 I-3I6.

Oldfield, E., Chapman, D. \& Derbyshire, W. (1972). Lipid mobility in Acholeplasma membranes using deuteron magnetic resonance. Chemistry and Physics of Lipids 9, 69-8I.

Russell, N. J. (1971). Alteration in fatty acid chain length in Micrococcus cryophilus grown at different temperatures. Biochimica et biophysica acta 231, 254-256.

SHAw, N. (I968). The detection of lipids on thin-layer chromatograms with the periodate-Schiff reagent. Biochimica et biophysica acta 164, 435-436.

Sud, I. J. \& Schaechter, M. (I964). Dependence of the content of cell envelopes on the growth rate of Bacillus megaterium. Journal of Bacteriology 88, 1612-1617.

Wells, M. A. \& DitTmer, J. C. (1963). The use of Sephadex for the removal of nonlipid contaminants from lipid extracts. Biochemistry 2, $1259-1263$. 